\title{
Narrativas y experiencias acerca del sentido de la vida y la muerte: etnografías del dolor y tramas familiares
}

\author{
Maria Ángela Aguilar \\ Master en Sociología (Instituto Universitário de Pesquisas do Rio de Janeiro) \\ Profesora en la Universidad Nacional de Salta \\ maaguilar@sinectis.com.ar \\ Maria Eugenia Suárez \\ Candidata a Maestra en Salud Pública (Universidad Nacional de Salta) \\ Profesora en la Universidad Nacional de Salta \\ meugeniasuarez@gmail.com
}

\begin{abstract}
Resumen El trabajo se enmarca en un proyecto de investigación en el que indagamos sobre "experiencias extremas" vinculadas a situaciones excepcionales de enfermedades y muertes a edades tempranas, vividas como acontecimientos trágicos que operan como quiebres de sentido en el grupo familiar, provocando rupturas abruptas en sus rutinas cotidianas e instalando un profundo hiato en sus experiencias vitales. La perspectiva etnográfica y el análisis de las narrativas hacen visible los diferentes modos en que los familiares resignifican el sentido de la vida y significan la muerte del que ya no está o del que sufre una enfermedad terminal. A la vez permiten mostrar el proceso que los va llevando a atribuir un sentido diferente a su propia existencia, donde la dimensión pedagógico-moral está presente, y los mecanismos encontrados para re-trazar el recorrido de sus vidas, creando nuevas tramas relacionales con "pares” en el dolor.
\end{abstract}

Palabras clave: acontecimientos trágicos; dolor; vida; muerte; identidad.

\section{Introducción}

— L trabajo forma parte de un proyecto de investigación más - amplio' en el que indagamos sobre "experiencias extremas", vinculadas a muertes de niños y jóvenes víctimas de gatillo fácil, violencia urbana y enfermedades terminales, vividas como acontecimientos trágicos $^{2}$ y que operan como quiebres de sentido en el grupo familiar, provocando rupturas abruptas en sus rutinas cotidianas e instalando un profundo hiato en sus experiencias vitales. Apelamos a la etnografía como una de las herramientas privilegiadas para el conocimiento de los diversos caminos que se encuentran para la construcción de sentidos

1. El proyecto dirigido por María Angela Aguilar se denomina "Acontecimientos trágicos y reconstrucción de sentidos" y su dependencia institucional, es el Consejo de Investigación de la Universidad Nacional de Salta (CIUNSa).

2. Para los fines de este artículo, entenderemos por tal un suceso cuya ocurrencia no era previsible y que irrumpe en la cotidianeidad de las vidas abriendo un hiato de difícil sutura y que origina una diversidad de "transformaciones en el espacio por las cuales las vidas de las personas entran en un terreno nuevo e imprevisto" (Das, 1995). 
vitales alternativos que pueden variar entre el repliegue en la intimidad, la vía de la justicia, la participación cooperativa y el reclamo mediante luchas sociales colectivas. Lo que buscamos es captar ese "núcleo de sentido" 3 en lo que entendemos que tienen todas las prácticas sociales.

En este artículo exploramos el proceso por el que atraviesan los familiares, particularmente las madres y los modos que van encontrando para gestionar el dolor y hacer comunicable el sufrimiento. Prestamos particular atención a las formas en que resignifican el sentido de la vida y significan la muerte del que ya no está o sufre una enfermedad terminal. Si bien la desaparición del cuerpo se experimenta en el espacio físico, el intento por recuperar una corporalidad de ese ser, de su paso por la vida, se materializa en diferentes rituales, y se expresa en las narrativas que construyen sus familiares que dan cuenta del valor social asignado a la vida, a la "vida digna" que tuvieron esos muertos, de ahí la doble dramatización: vida digna, vida truncada, a la que parece asistirse ante estos casos.

Junto a ello indagamos sobre un recorrido complementario que se imbrica con el anterior relativo al redelineado del sentido que estas mujeres/madres atribuyen a su propia existencia a partir del suceso trágico, que con frecuencia las lleva a involucrarse en actividades con las cuales demandan, reivindican, exigen justicia o acompañan y contienen a aquellos que pasan por experiencias similares en donde la dimensión moral y pedagógica está presente.

Trabajamos con registros visuales, fotográficos y los relatos que construyen los familiares en cinco casos seleccionados, producto del trabajo etnográfico.

\section{Historizando los casos}

Una breve referencia a cada caso permitirá delinear las coordenadas sociales que orientan sus prácticas, lugares de observación y tomas de posición.

Marga es integrante de "Madres del Dolor" de Santiago del Estero, agrupación que durante el "Juarismo"4, demanda contra el aparato represivo, el abuso y la impunidad. Su familia está conformada por ella, que tiene un puesto en el mercado, su marido que hace changas y cinco hijos, entre ellos Cori, el que fue asesinado por la policía a los 15 años en una razia por supuesto intento de hurto. Cori, era el ma- yor y el único que llevaba el apellido de Marga ya que nació cuando ella tenía 14 años. En sus relatos y su gestualidad se muestra como una mujer que no se deja llevar por delante y como dice, no tiene problema de encarar a nadie, incluido al gobernador.

Marita trabaja en "Madres del Dolor" de Buenos Aires, fundación integrada por un grupo de siete madres cuyos hijos fueron asesinados en diferentes hechos de violencia. Se ocupan de dar asesoramiento y contención a familiares y de promover la efectiva prestación de Justicia, pero no incorporan nuevos miembros. Está casada, su marido es ingeniero y tuvo tres hijos, todos universitarios, incluso José María que tenía 23 años cuando lo asesinan, era licenciado en comercio internacional y estaba trabajando. Formaron a sus hijos en principios liberales, señala que siempre se ha interesado por prácticas solidarias, aún antes de la muerte del hijo. Destaca que todas las madres tienen familias bien constituidas y entienden que ello les ayudó a enfrentar el drama.

Guadalupe está casada tiene tres hijos. A la menor, Serena, cuando tenía 2 años le detectan leucemia. Actualmente tiene 7, ha superado los tratamientos y se encuentra en periodo de control. Guadalupe trabaja en la fuerza policial como comisario. Tanto ella como su marido, que es empleado público, son oriundos del interior de la provincia. Cuenta que en el momento del diagnóstico su marido jugó un papel fundamental al llevar adelante la situación. Luego de un tiempo se sumó ella, junto con otras madres que pasaban por un problema similar y atendían a sus niños en el servicio de salud privado. Con ellas crearon la Fundación Hope ${ }^{5}$ destinada a contener, asesorar y ayudar a las familias procurando mejor la calidad de vida de los niños.

Yoli está casada. Tuvo dos hijos: Roberto David - a quien le detectan un cáncer a los 2 años y muere a los 5 luego de varias intervenciones y tratamientos - y otra hija menor. El marido es albañil, pasó por períodos de desocupación y ahora trabaja en plomería. Tiene fuertes convicciones religiosas y ello jugó un papel importante para enfrentar el proceso de enfermedad y posterior gestión del dolor, pero marca su distancia con las estrategias que ofrecen diferentes religiones para enfrentar el sufrimiento. Se muestra y se narra como una mujer decidida, de carácter y con una gran confianza en sí misma. Durante el período de tratamiento del hijo comenzó organizando actividades recreativas para los chicos internados en el hospital público. Posteriormente, crea la Fundación

3. Lo que siempre está "anclado en un horizonte común de ideas socialmente compartidas". Captar ese núcleo implica identificar "las lógicas situadas que deben ser entendidas a partir del punto de vista de los actores sociales que las ejecutan". (Segato - 2003).

4. Se refiere al período de casi 50 años en que Carlos Juárez, y luego su mujer gobernaron la provincia, una de las tantas vertientes locales del peronismo, sospechado de corrupción general.

5. Fundación hemato-oncología pediátrica. 
Roberto David y ha conseguido que varias empresas comerciales la apoyen.

La familia de Rómulo - quien tiene 13 años y padece $\mathrm{ALD}^{6}$, está conformada por su padre, militar retirado del ejército, actual empleado de mediana jerarquía en una empresa comercial; su madre Celia, que confecciona y alquila disfraces, pero se identifica como ama de casa y una hermana adolescente. Pertenecen a una clase media marcada por códigos morales estrictos y tienen como referente de prácticas y valores a familias conocidas del medio local. El peso de esta dimensión moral jugó un papel preponderante en el proceso previo al diagnóstico, generando en Celia un sentimiento ambivalente entre responder a su "instinto de madre" sobreprotegiendo al hijo - de lo que siente, la acusaba el entorno inmediato en tanto causaba los problemas del chico: poco disciplinado, amanerado, y, a su vez, seguir los dictados - hechos carne en ella - del modelo de familia legítima socialmente aceptada en ese entorno social. Después del diagnóstico ha estructurando su vida alrededor de la enfermedad del hijo, así como los tiempos de la casa y de sus integrantes.

\section{Memorias de la experiencia inaugural}

Entendemos que el sufrimiento vinculado a una experiencia individual adquiere sentido sólo en relación a determinada construcción socio-histórica y las relaciones de dominación que la atraviesan, que conforman el marco "cognitivo y operacional" para afrontar y encarar los problemas que acarrea el padecimiento (Otegui Pascual, 2009). Los modos de experimentar el dolor por la muerte de un hijo no son universalizables. "El dolor es un hecho situacional" (Le Breton, 1999, p. 9) no legible fuera de determinados marcos sociales.

Teniendo ello como referencia nos interesa rescatar la perspectiva de Geertz para quien el sufrimiento ${ }^{7}$ intenso y duradero es un desafío radical que amenaza disolver el sentido socialmente constituido de la vida, que la hace comprensible y que ofrece al hombre herramientas para orientarse en su mundo. Es un desafío a "nuestra experiencia por el cual el sentido de un particular esquema de vida amenaza disolverse en un caos de nombres sin cosas y de cosas sin nombre" (geertz, 1992, p. 99).

El tipo de sufrimiento sobre el que queremos enfatizar, más allá de las diferentes maneras de perci- birlo y encararlo, es el que se expresa en los cuerpos de modos más o menos persistentes, que desorienta la existencia y que inaugura una nueva experiencia ${ }^{8}$.

Uno de los sentidos que Benjamin le otorga a la experiencia y que aquí nos interesa es aquella que transfieren los adultos experimentados a las nuevas generaciones por medio de diversas modalidades de trasmisión oral, que se adquiere a lo largo de la vida, que sirve para la vida, que señala caminos. Es el tipo de experiencias que entiende se destruyen en los campos de batalla. Refiriéndose a las consecuencias de la I GM dice: "Entonces se pudo constatar que las gentes volvían mudas del campo de batalla. No enriquecidas, sino más pobres en cuanto a experiencia comunicable" (Benjamin,1973, p. 2). Podemos entonces interpretar que el sufrimiento al que nos referimos inaugura una modalidad de experiencia frente a la cual se carece de herramientas para enfrentarlo. Es traumática, portadora de una carga emocional de tal naturaleza que coloca a quien la vive en situación de desvalimiento frente a lo imprevisto. Priva de la palabra en cuanto posibilidad humana de comunicación. Es indecible.

Cuando la cosa se está complicando no puedo compartir nada con nadie, no puedo compartir lo que me pasa con nadie, me siento rara, no quiero ni hablar. ¡Tanta angustiada y no poder manifestarlo de ninguna manera! (Celia)

[...] el dolor que llevamos nosotros, yo te lo voy a graficar como... nosotros llevamos una mochila de dolor. Yo estoy con ustedes aquí, pero lo veo a mi hijo... eh..., puedo estar viendo una película, me acuerdo... hay veces lo siento en forma muy...muy difícil de explicarte. Dios quiera que nunca tengas que entender como es el dolor. (Jorge - Madres del Dolor Santiago del Estero)

Se trata para ellos de una experiencia intransferible e indeleble, que cargan consigo toda la vida y que es difícilmente comunicable. Para poder compartir esa experiencia y sentir ese dolor se necesita haber pasado por ella, única manera de entender el dolor que se siente. En cuanto a la trasmisión de esta experiencia, "el dolor es un fracaso del lenguaje" como lo entiende Le Breton (1999, p. 43). Arendt (2003) también plantea que el gran dolor como experiencia límite entre la vida y la muerte puede eclipsar todas las otras experiencias, por ende, ninguna sirve para lidiar con él. Es al mismo tiempo el menos comunicable y en ese sentido el más privado. Si bien ambos se refieren al dolor físico, podemos trasponerlo al dolor vinculado a pérdidas de seres

7. Junto al desconcierto y la sensación de una paradoja ética insoluble.

8. Aquí no referimos al sufrimiento producido socialmente, velado por la violencia simbólica y naturalizado como tal. 
muy próximos, que en tanto vivenciados como parte de uno mismo, como un hijo, produce un sentimiento similar, se siente en el cuerpo.

Según Susan Sontag (2005, p. 16): "La guerra rasga, desgarra. La guerra rompe, destripa. La guerra abrasa. La guerra desmiembra. La guerra arruina". Las experiencias extremas a las que nos referimos no son de guerra pero son disruptoras, irrumpen sin aviso. Frente a ellas la historia pasada, la trayectoria de los sujetos afectados no provee recursos para enfrentarla. Producto de acontecimientos vividos como catastróficos, produce en los próximos, en el nosotros más inclusivo un dolor que desarma, que desmiembra y ocupa todo el espacio vital de los más cercanos. La cita que sigue grafica este sentimiento:

[...] Y después a vivir con lo que queda ¿¿no? Nosotros decíamos, siempre nos llamábamos los cinquitos, siempre decíamos: "vamos los cinquitos" o sino yo no voy". Y es como que te mutilan un dedo, uno sigue haciendo las cosas porque podes vivir pero... te estás mirando las 24 horas del día el agujero que te queda. Yo creo que son las ausencias las que tienen más presencia (Marita).

En la mayor parte de los casos señalados el dolor marcó los cuerpos, cortó lazos, generó sentimientos de permanente vacío. Sin embargo podemos observar diferencias en los registros sobre lo ocurrido según que se trate de muertes abruptas o enfermedades graves. Cuando la muerte es intempestiva y no hay lapso entre la vida y la muerte, el quiebre de sentido parece más radical, primando el sentimiento de sufrimiento en los términos definido por Geertz. En estos casos las marcas temporales y espaciales que acompañaron al suceso se grabaron como a fuego en las memorias y parecen guardar tanto las señales del desquicio, del derrumbe de sus identidades como el punto de inflexión, la pausa, la bisagra que separa y articula el antes y el después que comenzaron a transitar a partir de ese momento:

[...] el 2 de julio del $97 \ldots$ a él lo matan a las 12 menos 20 en... un monte... (Marga)

Fue un viernes, un 12 de julio de 2002. Yo estaba cocinando, preparando la cena. Eran las 9 menos 10 de la noche. Yo me acuerdo la escena, estaba cocinando, lavarropas en marcha, suena el teléfono: "Juan Manuel, no jorobes, ¿cuánto necesitas?”... “No, mami, es en serio". Me dijo eso eh... sospeché, sospeché. Salí corriendo, no quería gritar... El grito salía solo.
No lo entendés. Te rompen todas las convicciones porque mirá, en mi familia todos decimos, menos mi marido, que queremos que nos cremen, que no se haga velorio [...] y sin embargo, en ese momento... "ipero yo lo quiero velar!”, le decía a mi marido... Yo me hubiera muerto, de verdad si no lo hubiera velado. (Marita)

Estas citas ejemplifican tanto las marcas que pararon el tiempo en el día, hora, momento y lugar fatídico como la irrupción en la vida cotidiana. Marita describe su rutina de ese día como podría haber sido la de cualquier otro, pero ahora la acompaña un sentimiento de desasosiego y, contrariamente a lo habitual, dejó de ser cotidiano pasó a ser único e irreversible. La desorientación, la imposibilidad de comprender y, por tanto, de comunicarse se expresa en la ruptura de sus convicciones, o sea de aquello que constituía su identidad y la del grupo familiar y que parecía tan sólida. No importa su visión en cierto sentido secularizada de la muerte, ahora, necesita velarlo. Necesita ese tiempo ritual que establece un cierto lapso, el tiempo de espera que le fue privado entre la vida y la muerte del hijo.

Distinta es la manera en que construyen la narrativa del recuerdo aquellas madres que atravesaron o atraviesan un proceso de enfermedad. Los tiempos son mucho más prolongados. Más que construir su propio tiempo de espera, lo que necesitan es acortar ese lapso que parece eterno entre los síntomas de la enfermedad y el diagnóstico nefasto. Es el período en el cual el sentimiento de desasosiego se instala, otro de los desafíos radicales que para Geertz irrumpen y amenazan al hombre. Los tiempos del desconcierto en los cuales "nuestro aparato de explicación ${ }^{10}$ no logra explicar cosas que claman por una explicación" (Geertz, 1992, p. 97) que suspenden la vida cotidiana instalando un tiempo de espera intolerable, como preanuncio de la tragedia. Luego el dolor que provoca la noticia del diagnóstico debe ser puesto parcialmente entre paréntesis para trazar las nuevas coordenadas de la existencia en pos de desafiar el presagio de la muerte y poder lidiar con la enfermedad.

Yo ya tenía mi angustia, mi dolor, yo sentía una cosa en el pecho que me daba tristeza, que me daba opresión, sentía ganas de llorar. [...] entonces él viene y me pregunta por qué lloras, "sabe qué doctor, que lo que usted me va a decir no es bueno, ahí él me dice que tenía cáncer. (Yoli)

[...] este año, ahora..., se me mezcla. El año pasado, ya todo el año digamos, vivimos su enfermedad con un 
diagnóstico. Previo a eso, todo el año habíamos estado indagando, pero sin saber qué era... O sea, que fue una etapa de presufrimiento, porque ves cosas muy raras que no podés manejar, que se manifiestan [...] Yo ya ahora estoy súper bien con respecto a cómo estaba. (Celia)

La trascripción de estos textos remite a experiencias de dolor, pero expresa otras temporalidades y requieren modos diferentes de vivirlo y encararlo. En estos casos se manifiesta una sensación de confusión que se expresa en la dificultad de recordar fechas y lugares de la primera etapa de desconcierto y angustia.

Las estructuras de significación en virtud de las cuales los agentes dan forma a su experiencia están mediadas por una serie de concepciones - ideales, hipótesis, obsesiones, juicios de valor - pero no es precisamente un campo uniforme en el que el mundo de las ideas toma forma, sino que está lleno de imprecisiones (Geertz, 1973). Es en el análisis de los detalles en los escenarios en los que se desenvuelve donde cobran realidad las trayectorias que son propias a cada experiencia. En este sentido, la enfermedad y sus síntomas puede entenderse como un conjunto de significados que se construye y articula en un contexto cultural. Al considerar las narrativas sobre la enfermedad, cuando se trata de relacionar los sentidos que tiene el cáncer, los significados culturales que se le atribuyen, implica también una ruptura en la vida de la persona, por las representaciones que rodean a la enfermedad.

Sontag (2003) sugiere que la aversión social que provoca este tipo de enfermedad, es que se la asocia a la muerte, se presenta ligada a metáforas que suponen unos procesos vitales que corrompen y consumen la vida de las personas. De allí, que la asunción de la enfermedad suele provocar todo tipo de emociones encontradas ya que las representaciones sobre la misma influyen en el padecimiento. Esta situación se agudiza si el cáncer afecta el cuerpo de un infante, algo así como "la vida plena que se corta por el deterioro vertiginoso del cuerpo". Para Guadalupe luego del diagnóstico y el inicio propiamente del tratamiento cuenta lo siguiente:

Cuando hay un peligro real, ahí te quedan dos opciones: o te quedas quieta y no haces nada, o haces todo lo contrario, tratas de hacer todo. Ya he pasado por varias etapas durante el diagnóstico. Crees que el médico se ha equivocado, que es un error, que no puede ser. Se culpa...que se yo, miles de cosas que aparecen en tu cabeza que en ocasiones te paralizan [...] Yo he llegado al extremo de que me olvidé de escribir... tenía que controlar documentación que firmaba el jefe de policía y yo no me acordaba como firmar. (Guadalupe)
La reconstrucción de marcos de sentido en los que cobra valor su existencia es gradual y se manifiesta de un modo variable entre los casos. Pero en general el sufrimiento debe contenerse ya que la situación exige a las madres rearmarse para encarar y acompañar el tratamiento y mitigar el dolor del hijo.

\section{Modos de resignificar la existencia. De cómo lo indecible puede ser puesto en palabras o en actos}

En sus estudios sobre el genocidio nazi Pollak (2006) describe el tipo de experiencia a la que nos referimos como "experiencias extremas". Frente a ellas el sentido del juego social del que se forma parte, el saber adquirido en la práctica y que orienta las prácticas cotidianamente, es el que ha sido puesto en cuestión, suspendido de una u otra manera frente a la situación dramática e imprevisible, para la cual no hemos sido socializados, la que no se logra comprender en los primeros momentos, por falta de una memoria compartida que permita "decodificarla", colocando a los sujetos frente a la experiencia del "sinsentido". Esto es lo que pretendimos reflejar en el apartado anterior.

Ese desvanecimiento de sentido de todo lo que parece significativo no puede perdurar en el tiempo ya que llevaría al aislamiento, la locura o a la propia muerte, los sujetos afectados van buscando instalarse en ese nuevo contexto, redefiniendo sus identidades y sus relaciones con los otros. Prestaremos atención a los modos de gestión del dolor, los mecanismos encontrados para re-trazar el recorrido de sus vidas, los criterios de visión y apreciación del mundo que los rodea a partir de esa experiencia extrema a la vez que inaugural, que permite generar nuevos recursos y un nuevo lenguaje para poner palabras, actuar, hacer comunicable lo indecible.

En este proceso de rearmado de la existencia una de las primeras cuestiones que se vuelve importante es la búsqueda de "otros" que puedan ayudar a explicar, comprender y encarar la nueva etapa. Frente al panorama de "otros" a los que contactar hay una distinción clave entre los especialistas, que difieren en función de cual sea su tragedia (abogados, médicos, asistentes sociales, psicólogos, enfermeras) y los "pares en experiencia traumática". Pero en esta reconstrucción de la trama vital por vía del tejido de nuevos lazos, hay una diferencia sustantiva entre unos y otros.

Los primeros son agentes especializados, que disponen de saberes expertos y pueden orientarlos profesionalmente. En cierto sentido se vuelven familiares 
a sus vidas, pero también los confunden y discrepan con ellos:

Crees que el médico se ha equivocado, que es un error, que no puede ser... miles de cosas que aparecen en tu cabeza que en ocasiones te paralizan. Acá en Salta hay un sólo oncólogo pediatra, así que no tenés muchas opciones o bien tenés que pensar en irte de acá. O sea, es una serie de conflictos que se vienen encima que no es fácil de manejar. (Guadalupe)

Son las voces expertas, necesarias para enfrentar ciertas etapas del proceso, pero su lenguaje y la autoridad de la que están investidos tiende a expropiar la experiencia y la voz de la víctima sustituyendo su autoridad sobre el dolor, y su condición de doliente por criterios técnicos, legitimando su propio discurso profesional (Das, 2008, p. 409).

Los segundos, en cambio, son pares en experiencia traumática, son otros que puedan comprender, porque "lo han vivido" y, entonces, habilitados por la experiencia, compartir y orientar su búsqueda de tratamiento, de explicación, de justicia, de luchas. Son esos otros con potencialidades de transformarse en un "nuevo nosotros". Son "iguales" con relación a lo que en ese momento se ha convertido en el eje de sus vidas. Junto a ellos, que como ellos están marcados, crean lazos y como dice Pollak, buscan maneras de existir en situaciones nuevas.

De repente en una marcha me dice un señor: "venimos de Berizzo a acompañarlos, estamos con ustedes". Yo pensaba, pensar que si esto pasaba en otro barrio, yo no acompañaba porque me parecía que no era de mi pertenencia. A partir de ahí, de las cartas, los libros, los mensajes, de todo lo que sucedió aprendí la importancia de acompañar al otro, estar en presencia con el otro ¿no? (Marita)

Esos otros que antes estaban fuera de su espacio relacional, se visibilizan, pasan a existir. Con diferencias, la búsqueda y la necesidad de contactar a "pares de experiencia" es uno de los primeros imperativos. A partir de allí comienza a abrirse un abanico de modos y estrategias encontradas para gestionar el dolor y re-trazar el recorrido de sus vidas.

Teniendo como primer sustrato la experiencia compartida de sufrimiento, que con frecuencia los lleva a constituir una asociación, una de las primeras diferencias tiene que ver nuevamente con el tipo de acontecimiento. Se gestiona el dolor y se articulan los vínculos relaciones de manera diferente según este se construya como un accidente excepcional, ajeno a la voluntad de las partes o, por el contrario, sea posible identificar un culpable de la muerte violenta y diferentes responsabilidades institucionales y gubernamentales.

Si bien estas diferencias dan lugar a modalidades diversas de encarar el futuro y divergen con relación al modo de organizarse y a sus demandas, es importante recordar que el reparto del sufrimiento es socialmente diferencial en función de la inserción de los sujetos en tramas relacionales de dominación de clase, género y etnia que, a su vez, se imbrican entre sí. Por más drástico que sea el quiebre de sentido, el re-trazado de las trayectorias no se realiza a partir del vacío, no los instala en el lugar de una tabula rasa. Los grupos subordinados con respecto a alguna o varias de las tramas relacionales señaladas están expuestos en mayor medida a enfrentarse a este tipo de acontecimientos ${ }^{11}$. Encontramos también diferenciales en las maneras de sufrir y de hacer frente al dolor, dándole un nuevo sentido a lo que se vivió como completamente sinsentido. Trabajaremos sobre un par de relatos para visibilizar diferentes modos de materializar ese tránsito.

Me habla de Papá Noel, que ya se acercaba la fecha de Papá Noel. Entonces yo le digo "sabes qué papi, yo no voy a ir a buscar el regalo de los chicos este año. Porque vos estás enfermito y yo no te quiero dejar solo". Entonces el vino y me dijo "no Yoli vos tenés que ir a buscar los juguetes porque yo voy a descansar. Y me dice:"Vos sos la mejor mamá del mundo y los otros chicos no tienen una mamá como vos"... Él fue mi maestro.

[...] hace un dibujo en el jardincito porque la maestra decía que hagan dibujo libre. Y el mapa que él hace es el camino que yo hago al cementerio cuando voy... y le dice "yo hice el mapa para que laYoli encuentre el tesoro". ¿Entendés?

[...] Al otro día se levanta con la idea que estaba en un jardín lleno de flores blancas, "Yoli, mirá todo esto está lleno de flores ¡Qué lindas las flores! Hay que cuidarlas".

[...] lo enterramos el sábado en la tarde, el domingo estuve en casa, el lunes a la mañana me levanté, me cambié y me fui al hospital.

[...] Ahí yo me fui de la Fundación y seguí lo que es consiguiendo cosas para los chicos [...] ella es una señora de mucha plata. Y por ahí tenía la soberbia de decir "yo tengo plata y soy la dueña del mundo"... y dice que yo tenía que hacer una Fundación si quería seguir.... Ajá!!! Dije: "Yo hago la Fundación” (Yoli).

Estos fragmentos de la narrativa de Yoli son ilustrativos de cómo se entraman ambas dimensiones. La vinculada al modo en que va resignificando la imagen de la corta vida del hijo: generoso, preocupado por los 
demás, capaz de consolarla y de transformarse en su maestro, su guía. Un ser superior que le dio indicios del más allá, que dejó huellas de sus condiciones "extra humanas", que no sólo aceptó su muerte, sino que la preanunció, así como preanunció su lugar de entierro y dejó trazado el mapa para que su madre, pueda llegar sin perderse y encontrar su tesoro. La otra dimensión, atinente a la forma que encuentra de darle un nuevo sentido a su propia existencia, parece desprenderse de la anterior. El "trabajo social" que Yoli lleva adelante, que había iniciado antes de la muerte del niño, se transforma en su actividad principal, el motor de su vida que lleva adelante en un estilo marcadamente personalizado. Es la puesta en práctica, es el modo de cumplir el mandato que el hijo le dejó. Actúa entonces no sólo en su memoria, sino en su representación. A la par lo hace con aquellos que siente próximos no apenas por compartir el dolor, sino, porque ocupan posiciones semejantes en las tramas relacionales mencionadas anteriormente y, por ende, comparten estilos de vida similares $^{12}$. En este movimiento se distancia y deja fuera a aquellos que por modos de existencia vinculados a posiciones dominantes les priva del sentido de la ubicación y los coloca fuera de lugar ${ }^{13}$.

Ese trabajo se materializa en la creación de la Fundación que lleva el nombre del hijo y la posibilidad de inaugurar un salón para la atención de niños que están en situación ambulatoria. Logro personal y personalizado, se entreteje con otro sentimiento que tiene que ver con la cuestión del reconocimiento. Esa marca, esa impronta, parece ir transformándola en alguien digna de reconocimiento, respeto y admiración. Este movimiento, a la par que hace visible su drama, también enaltece y dignifica su persona como alguien capaz de enfrentar tanto dolor transformándolo en un servicio, moralmente digno de reconocimiento.

Veamos ahora otro relato:

Siempre digo que mi hijo era muy deportista, era muy práctico, hacia deportes de todo tipo $\mathrm{y}$, siempre digo, si hubiera sido que tenía que vivir postrado, hubiera sido mucho peor. Padecer esas enfermedades imposibles y que uno sabe que no van a tener cura, hay muchas cosas peores ¿no es cierto? Tuve 23 años gloriosos y el dolor también lo compenso por ese lado.... Y bueno, y a partir de ahí el acompañamiento de mucha gente, el aprendizaje.

$[\ldots .$.$] nosotros como que somos una gran familia { }^{14}$. Hay gente que nos pregunta cómo podemos con tanto dolor. Pero nosotros, como que lo tomamos como algo natural de la vida, porque sabemos que lo vamos a tener que soportar... no es acostumbramiento, es aprender a vivir con el dolor que es algo muy distinto. [...] Y los chicos están siempre presentes, acá es donde más hablamos de ellos...Nosotras no queríamos poner gente desconocida (en la Fundación)... por los conflictos, nosotras nos llevamos muy bien.

Han venido muchos familiares diciendo que sus psicólogos le han dicho en un momento de desesperación "Vayan acérquense, hablen a las madres del dolor" como que nos han tomado como contenedoras, un rol de contenedoras sociales...Y yo creo que... es importante, porque para eso no se estudia en ningún lugar... Eso sale de tu alma, de tu dolor, no hay que ir a ninguna Universidad para saber lo que vos sentís, y lo que le podés brindar al otro.

Y no hemos parado, yo digo que nos dieron cuerda. Porque es estar en casa y estar pendiente si pasó algo, mira hubo una tragedia, alguien se comunicó con la familia, es decir, es el compromiso pero no es una carga. Es el sentirse bien en cada acción, es como que gratifica. (Marita)

El tono que atraviesa estos fragmentos y el tipo de cuestiones que se enfatizan, son indicativos de que estamos frente a un modo de gestionar el dolor y reorganizar la existencia que marca distancias con el anterior. Distancias que expresan diferentes posiciones y disposiciones desde las cuales se re-traza esta etapa de la vida. En este caso el discurso pone la acción en un "nosotros". Nosotros que se muestra ambivalente al pretenderse inclusivo a la par que excluyente. Incluye al grupo de madres que son conocidas, que tienen familias estructuras y parecidas, que decidieron enfrentar el dolor de determinada manera. Excluye, en su carácter de iguales, a otros familiares que aunque pasaron por un dolor similar, no les resultan suficientemente confiables para conformar ese nosotros sin generar conflictos, más allá de los que ellas están dispuestas a sostener. Hacia esos otros, pares en el dolor, está dedicada a la asociación, son los destinatarios. A ellos acompañan, asesoran, contienen. A ellos les enseñan, a partir del aprendizaje que les dio el dolor, única "institución" válida de acreditación. Así se instituyen y las instituyen como referentes frente a aquellos que les toque pasar por tragedias similares. En ese senti-

12. Yoli, en una primera etapa se integra a otra Fundación la que abandona por las distancias que la separan en condiciones de existencia, en estilos de vida y en la forma de encarar la gestión de la organización. Yoli tiene un modo personalizado e informal de gestionar, de buscar "ayudas" y adherentes, de decidir lo que hacer y lo que no, que generaba diferencias con aquellas madres.

13. Esta cita de Yoli es ilustrativa: "Por ahí ella te planteaba que sí, que a ella se le murió el hijo, que ella sabe lo que es el dolor, que la última Navidad ellos brindaron con champagne y comieron caviar y qué sé yo. O sea vos le hablás eso a una mamá que no tiene para comer un pedazo de bife, o sea, ¿Me entendés?"

14. Se refiere a las madres que integran la fundación "Madres del Dolor" de Buenos Aires. 
do, son pioneras y como tales abren camino y se lo allanan a los que siguen detrás. Se vuelven "expertas" en lidiar con la nueva situación y por tanto, están habilitadas para trasmitirla y apaciguar el dolor de otros. El estilo de trabajo por el que optaron, porque "dispuestas" a ellos, es la permanente gestión de recursos materiales y simbólicos y la racionalización de su uso mediante un compromiso descomprometido.

Los hijos tienen una presencia constante, impresa espacialmente en el mural de fotos de la Asociación y en las permanentes charlas que mantienen en las instalaciones de la asociación, su principal lugar de encuentro. Esa manera de actualizar las ausencias presenta un tono más secular que la que observábamos en el caso de Yoli. Sin embargo hay también similitudes, por ejemplo, en el juego de inclusión - exclusión de nosotros/yo versus ellos, los destinatarios de su misión que tienen algo de mí/nosotros en tanto pares en el dolor. El trabajo obsesivo e incansable mediante el cual, a la vez que un intento de suturar, actualiza la presencia del ausente, es otro punto en común.

\section{Escenarios de ritualización}

Otro de los modos encontrados para gestionar el dolor se manifiesta por medio de prácticas rituales, en tanto tienden a mitigar la angustia, el sufrimiento y la incertidumbre. Inscriptas en determinados escenarios - en tanto espacios vividos, practicados - operan como campo de fuerza de emociones y valores que circulan y concentran significados semánticos del dolor. Por intermedio de los rituales se efectúa un trabajo que transforma lugares en espacios (en el sentido dado por De Certeau, 1996). Un ritual no es apenas un esquema de significación, sino que es una forma de interacción social, es decir, la manera en que es compartido con los otros miembros supone un corpus de experiencias y creencias comunes o, al menos, no desconocidas. Para los familiares de víctimas que conforman asociaciones, la experiencia compartida es el fundamento de toda iniciativa que como grupo realizan. Pero para que estas se lleven a cabo efectivamente existe un trabajo constante de ritualización, base de la legitimación del grupo.

Los festejos y encuentros relacionados a alguna actividad son ocasiones de socialización. Por vía de ellos se ponen en prácticas actos rituales que indican las propiedades en que están envueltas las experiencias compartidas y a partir de dicha experiencia se crea un universo común de referencias. Pero los símbolos no son solamente indicadores de categorías de clasificación a partir de las que se ordena el mundo, sino que ponen en acción una "serie de dispositivos que son evocadores cuyo uso tiene como fin el suscitar, encausar y domesticar las emociones fuertes como el odio, el miedo, el dolor", dicho de otro modo, tienen una intencionalidad (Turner, 1969, 53). ${ }^{15}$ A la vez, sellan una comunidad de pertenencia afectiva.

Así, durante los eventos que organizan las asociaciones de familiares se ritualizan prácticas que por sus propiedades buscan no apenas hacer de esa experiencia un acto compartido, sino que también tienen como fin encauzar las emociones que están presentes en las distintas situaciones que se vivencian en el curso de la enfermedad, de los padecimientos, de la muerte. En los festejos de aniversarios y conmemoraciones se observan ceremonias que tienen un carácter de solemnidad para sus participantes.

Este es el caso de una práctica observada durante un ejercicio etnográfico en ocasión de la inauguración del local de la Fundación Roberto David. La misma tiene que ver con el acto de arrojar globos al cielo. Cada globo lleva el nombre de un niño que padece cáncer o bien que falleció. Todos los presentes se reúnen en un espacio exterior del local, se colocan alrededor de la persona que sostiene los globos e inmediatamente se los arroja hacia el cielo. A medida que ven alejarse los globos se produce un notable silencio entre los participantes, algunos, afectados por una situación de luto reciente, no ocultan su llanto y se abrazan a otros familiares. Dicha ceremonia, que por sus referencias simbólicas y contornos emotivos moviliza una serie de metáforas que están presentes en el hecho mismo de observar cómo esos globos que contienen los nombres de los niños - no hay distinción entre los fallecidos y los que están con vida - se alejan hacia el cielo hasta perderse, contiene varias dimensiones a tener en cuenta, particularmente la ambigüedad que se pone de manifiesto en dicho acto. Por un lado la presencia implícita de la muerte del niño enfermo en el momento de soltar los globos, metáfora que remite al hecho de "dejarlo ir", de habilitar la partida de esa vida. Al mismo tiempo remite al recuerdo, actualiza la presencia de aquellos que ya no están mediante un ejercicio de memoria. En un juego en que presencias y ausencias se invierten y se acoplan. Los símbolos y sus relaciones tal como aparecen en este homenaje se entrecruzan con los sentidos atribuidos a la muerte pero también a la vida, o con la singularidad de una vié. (Deleuze, 2007) ${ }^{16}$. Por otro lado y complementariamente los globos que se elevan al cielo remiten a otra dimensión simbólica vinculada 
a creencias religiosas ${ }^{17}$, en tanto aquel es el destino final que se le atribuye a las almas de niños/ángeles. Los globos entonces van a su encuentro en una búsqueda de actualizar el lazo de unión con los vivos.

Otro de los registros, con similar carga simbólica son los festejos de cumpleaños en salas de oncología infantil donde las familias pasan largos períodos de tiempo durante los tratamientos. Estos son interpretados como manifestaciones que se oponen al llanto, o la angustia que implica llevar adelante el padecimiento de la enfermedad y, con ello, la posibilidad cercana de la muerte, "de no poder superar el tratamiento". En este sentido el recurso a las fiestitas de cumpleaños se transforma en aquello que se opone a toda esa situación. Son actos que inauguran un nuevo momento, especie de paréntesis que permite al menos por un corto período de tiempo olvidar todo lo otro. Las festividades son vividas como una forma concreta donde se manifiesta la vida misma, que irrumpe con los payasos, la música, el cotillón, los regalos y que acompaña, a la vez que se opone, a los acontecimientos serios (Bakhtin, $1987)^{18}$. Al oponerse provoca una especie de liberación efímera, una abolición transitoria de los estados de opresión.

Lo que más te mata es la depresión. Y el chico, si vos lo estimulas con juegos, fiestas, es que la vida continúa. Y el niño a pesar de todo lo que vive tiene que continuar su vida [...] El hecho de que esté suprimi$\mathrm{do}^{19}$, no lo hace que esté aislado. Entonces, por eso nosotros generamos esas fiestitas que se juntan todo ellos con sus hermanitos, y bueno, tratamos de que sea inolvidable. (Guadalupe)

En los festejos, por un lado se resignifica la vida, "es la vida misma la que se juega e interpreta" al tiempo que aparta, al menos provisoriamente, la posibilidad de la muerte. Es una carrera de la vida, por tomarse un tiempo más antes de la muerte, aunque en algunos casos esta se haga inevitable, así nos comenta otra entrevistada:

Entonces la madre nos contó que iba a cumplir 15 años, que le quería hacer la fiestita, ya habían comprado los suvenires. Entonces nosotras nos ponemos en campaña de que le vamos a hacer el cumpleaños, como sea que lo tenga al cumpleaños de 15 . Una semana antes viene la madre y nos dice "no, no lo va- mos a hacer al cumpleaños”, el 28 de agosto cumplía los 15 [...]. Y yo ese día antes de que muera hablo con la madre y le digo:" ya tenemos el salón y ya vamos a conseguir la comida, las tarjetas, cuando ella quiera hacemos el cumpleaños". Y ya estábamos organizando toda la fiesta, y "decíle a Claudia que no se preocupe si se le cae el pelo, le vamos a buscar la peluca más linda, el vestido más lindo". Y al día siguiente ella murió (Yoli).

La importancia que adquieren los festejos en el proceso de enfermedad se asemeja a una reiteración invertida de lo que llamamos experiencia inaugural, en el sentido que instalan una suspensión temporaria de la rutina. Las fiestas, celebraciones alegres, con regalos y diversión operan como un corte de la actual rutinización en la vida de los niños y sus madres, donde la incertidumbre y la angustia se volvieron sentimientos cotidianos. Estas prácticas rituales, paréntesis recreativos frente a la muerte que se avecina, que amenaza y contra la que se lucha, podemos leerlas desde diferentes registros. El que propone Bajtin enrelación a los festejos populares. Para este autor las fiestas han estado siempre ligadas a períodos de crisis y en su base encuentra una concepción determinada del tiempo, tanto cósmico como biológico e histórico, siendo la muerte, la resurrección y la renovación uno de los aspectos esenciales que las acompañan. La segunda lectura, desde el psicoanálisis, habilita a interpretarlas como rituales de denegación ${ }^{20}$ a través de los cuales postergan la angustia por un lapso de tiempo que se prolonga con el tiempo y esfuerzo invertido en los preparativos. La denegación es entonces una forma de defensa contra la angustia. Al resignificar la vivencia de cuerpo fragmentado, se busca totalizarlo en un acto ritual que pone en suspenso la amenaza de muerte y la angustia que esta ocasiona. Mientras el primero señala una "huida provisoria de los moldes de la vida ordinaria" (Bajtin, 1987, 7) encarnada en estos casos en las rutinas hospitalarias, de las que se liberan temporalmente, el segundo, en cambio, podemos entenderlo como una forma de dar sentido a la vida, apartando provisoriamente el temor a la desintegración que implica la muerte.

En estas páginas pretendimos mostrar el proceso que los familiares comienzan a transitar a partir del evento crítico y los diversos caminos encontrados para enfrentar el dolor que se va "encarnado"

\section{En sentido amplio.}

18. Las fiestas tienen siempre una relación profunda con el tiempo. Tienen una concepción determinada del tiempo cósmico, biológico e histórico. Las fiestas históricamente, han estado ligadas a períodos de crisis, de trastornos en la vida de la naturaleza, la sociedad y el hombre. La muerte y la resurrección, las sucesiones y la renovación constituyeron siempre los aspectos esenciales de la fiesta (Bakhtin, 1987, p. 8).

19. Con las defensas bajas por el tratamiento.

20. En tanto inconsciente denegación de la existencia, de lo que ocurre. Desde la perspectiva freudiana el pánico reenvía inconscientemente al estado de indefensión radical del momento del nacimiento. (Murillo, 2008). 
en ellos, diferencias que se vinculan con las características del evento pero también con las trayectorias sociales de los afectados. Tratamos de develar cómo los relatos y los rituales efectúan un trabajo que va transformando lugares en espacios vividos (De Certeau, 1996) que, de modo similar a las fronteras, establecen lazos y modos de comunicación entre los "propios", al tiempo que separan, establecen distancia con "otros" que no fueron marcados por la experiencia extrema. Entendemos que los límites entre dentro y fuera son difusos, presentan matices y una variada gama de "nosotros" y de "otros". Podemos pensar al antropólogo como ocupando un lugar intersticial al habilitar el testimonio, el espacio para decir o, según los casos, para mostrar por medio de los cuerpos. Das $(2008,456)$ afirma que sin pretender apropiarnos del dolor del que sufre, el texto etnográfico "puede servir como un cuerpo de escritura que permita que el dolor del otro se exprese en él”.

LE BRETON, David. Antropología del dolor. Barcelona: Seix Barral, 1999.

MURILlO, Susana. Colonizar el dolor. Buenos Aires: Clacso Editorial, 2008.

OTEGUI PASCUAL, Rosario. El sufrimiento, la forma socio-cultural del dolor. In: GRIMBERG, Mabel. (Org.). Experiencias y narrativas de padecimientos cotidianos. Buenos Aires: Antropofagía, 2009.

POLLAK, Michel. Memoria, olvido y silencio: la producción de identidades frente a situaciones límite. La Plata: Ediciones Al Margen, 2006.

SEGATO, Rita. Las estructuras elementares de la violencia: contrato y status en la etiología de la violencia. In: ____. Las estructuras elementares de la violencia: ensayos sobre género entre la antropología, o psicoanálisis y los derechos humanos. Buenos Aires: Universidad Nacional de Quilmes; Prometeo, 2003.

SONTAG, Susan. La enfermedad y sus metáforas. Buenos Aires: Editorial Taurus, 2003.

SONTAG, Susan. Ante el dolor de los demás. Buenos Aires: Alfaguara, 2005.

TURNER, Víctor. El proceso ritual. Madrid: Taurus, 1969.

GEERTZ, Clifford. La interpretación de las culturas. Barcelona: Gedisa, 1992. 


\title{
Narrativas e experiências sobre o sentido da vida e da morte: etnografias da dor e tramas familiares
}

\section{Resumo}

O trabalho se situa em um projeto de pesquisa no qual indagamos sobre "experiências extremas" vinculadas a situações excepcionais de enfermidades e mortes em tenras idades, vividas como acontecimentos trágicos que operam mudanças de sentido no grupo familiar, provocando rupturas abruptas nas rotinas cotidianas e instalando um profundo hiato nas experiências vitais. A perspectiva etnográfica e a análise das narrativas tornam visíveis os diferentes modos pelos quais os familiares ressignificam o sentido da vida e significam a morte de quem já não está ou do que sofre uma doença terminal. Ao mesmo tempo permite mostrar o processo que vai levando-os a atribuir um sentido diferente à sua própria existência, em que a dimensão pedagógica-moral está presente, e os mecanismos encontrados, para retraçar o percurso das suas vidas, criam novas tramas relacionais com "pares" na dor.

Palavras-chave: eventos trágicos; dor; vida; morte; identidade.

\section{Narratives and experiences about the meaning of life and death: ethnographies of pain and family interactions}

\begin{abstract}
This work is part of a research project in which we investigated on "extreme experiences" related to exceptional situations of illness and early death. These experiences are felt as tragic events that serve as breakdowns in the meaning of family life, causing abrupt breaks in daily routines and installing a deep gap in family life experiences. Ethnographic perspective and the analysis of narratives make visible the different ways in which families redefine the meaning of life and signify the death of those who pass away or who suffer a terminal illness. At the same time they reveal the process of attributing a different meaning to one's own existence - which involves a pedagogical and moral dimension - and the mechanisms used by the family group to re-trace their lives' path, creating new relational networks with their "peers" in pain.
\end{abstract}

Keywords: critical events; pain; life; death; identity.

Data de recebimento do artigo: 01/05/2011

Data de aprovação do artigo: 29/07/2011 